\title{
Antioxidative phytochemicals from Rhododendron oldhamii Maxim. leaf extracts reduce serum uric acid levels in potassium oxonate-induced hyperuricemic mice
}

Yu-Tang Tung ${ }^{1 \dagger}$, Lei-Chen Lin² ${ }^{2 \dagger}$, Ya-Ling Liư ${ }^{3}$, Shang-Tse Ho ${ }^{3}$, Chi-Yang Lin ${ }^{3}$, Hsiao-Li Chuang ${ }^{4}$, Chien-Chao Chiu ${ }^{5}$, Chi-Chang Huang ${ }^{1 *}$ and Jyh-Horng $\mathrm{Wu}^{3^{*}}$

\begin{abstract}
Background: Some of the genus Rhododendron was used in traditional medicine for arthritis, acute and chronic bronchitis, asthma, pain, inflammation, rheumatism, hypertension and metabolic diseases and many species of the genus Rhododendron contain a large number of phenolic compounds and antioxidant properties that could be developed into pharmaceutical products.

Methods: In this study, the antioxidative phytochemicals of Rhododendron oldhamii Maxim. leaves were detected by an online HPLC-DPPH method. In addition, the anti-hyperuricemic effect of the active phytochemicals from $R$. oldhamii leaf extracts was investigated using potassium oxonate $(\mathrm{PO})$-induced acute hyperuricemia.

Results: Six phytochemicals, including (2R, 3R)-epicatechin (1), (2R, 3R)-taxifolin (2), (2R, 3R)-astilbin (3), hyposide (4), guaijaverin (5), and quercitrin (6), were isolated using the developed screening method. Of these, compounds 3, 4, 5, and 6 were found to be major bioactive phytochemicals, and their contents were determined to be $130.8 \pm 10.9$, $105.5 \pm 8.5,104.1 \pm 4.7$, and $108.6 \pm 4.0 \mathrm{mg}$ per gram of EtOAc fraction, respectively. In addition, the four major bioactive phytochemicals at the same dosage $(100 \mathrm{mmol} / \mathrm{kg})$ were administered to the abdominal cavity of potassium oxonate (PO)-induced hyperuricemic mice, and the serum uric acid level was measured after $3 \mathrm{~h}$ of administration. H\&E staining showed that PO-induced kidney injury caused renal tubular epithelium nuclear condensation in the cortex areas or the appearance of numerous hyaline casts in the medulla areas; treatment with $100 \mathrm{mmol} / \mathrm{kg}$ of EtOAc fraction, (2R, 3R)-astilbin, hyposide, guaijaverin, and quercitrin significantly reduced kidney injury. In addition, the serum uric acid level was significantly suppressed by $54.1,35.1,56.3,56.3$, and $53.2 \%$, respectively, by the administrations of $100 \mathrm{mmol} / \mathrm{kg}$ EtOAc fraction and the derived major phytochemicals, (2R, 3R)-astilbin, hyposide, guaijaverin, and quercitrin, compared to the PO group. The administration of $10 \mathrm{mg} / \mathrm{kg}$ benzbromarone, a well-known uricosuric agent, significantly reduced the serum uric acid level by $45.5 \%$ compared to the PO group.
\end{abstract}

Conclusion: The in vivo decrease in uric acid was consistent with free radical scavenging activity, indicating that the major phytochemicals of $R$. oldhamii leave extracts and the derived phytochemicals possess potent hypouricemic effects, and they could be potential candidates for new hypouricemic agents.

Keywords: Rhododendron oldhamii maxim, Leaf, Phytochemical, Online HPLC-DPPH, Hyperuricemia

\footnotetext{
* Correspondence: d301090007@gmail.com; eric@nchu.edu.tw

${ }^{\dagger}$ Equal contributors

'Graduate Institute of Sports Science, National Taiwan Sport University,

Taoyuan 333, Taiwan

${ }^{3}$ Department of Forestry, National Chung Hsing University, Taichung 402,

Taiwan

Full list of author information is available at the end of the article
}

C Biomed Central
(C) 2015 Tung et al. Open Access This article is distributed under the terms of the Creative Commons Attribution 4.0 International License (http://creativecommons.org/licenses/by/4.0/), which permits unrestricted use, distribution, and reproduction in any medium, provided you give appropriate credit to the original author(s) and the source, provide a link to the Creative Commons license, and indicate if changes were made. The Creative Commons Public Domain Dedication waiver (http://creativecommons.org/publicdomain/zero/1.0/) applies to the data made available in this article, unless otherwise stated. 


\section{Background}

The major function of xanthine oxidase (XOD) is to catalyze the oxidation of hypoxanthine to xanthine and to further catalyze the oxidation of xanthine to uric acid in purine metabolism [1]. Excess amounts of uric acid in the body result in the deposition of urate crystals in the joints and kidneys, causing inflammation as well as gouty arthritis and uric acid nephrolithiasis [2, 3]. Recent studies also noted that hyperuricemia is associated with a risk of chronic nephritis, renal dysfunction, cardiovascular diseases, hypertension, diabetes, and metabolic syndrome $[4,5]$. Thus, there has been increasing interest in the search of more effective or novel bioactive compounds in order to improve the insufficient uric acid excretion from a wide variety of traditional herbal plants [6-8].

The genus Rhododendron is widely distributed throughout most of the world, with the exception of Africa and South America [9]. Some members of the genus Rhododendron were used in traditional medicine for arthritis, acute and chronic bronchitis, asthma, pain, inflammation, rheumatism, hypertension, and metabolic diseases [10-12]. In addition, Rhododendron sp. used in Unani system of medicine for treatment of gout [13, 14]. Recent studies have shown that many species of the genus Rhododendron contain a large number of phenolic compounds and antioxidant properties that could be developed into pharmaceutical products $[15,16]$. In addition, recent studies noted that phenolics are strong XOD-inhibitors [17] and have the potential to lower the risk of hyperuricemia and gout [18]. In previous studies, it was found that Rhododendron yedoense contains large amounts of flavonoids and shows excellent XOD-inhibitory activities [19]. Therefore, methanolic extracts of $R$. oldhamii leaves may be good candidates for further development as clinically relevant antihyperuricemic agents. However, to the best of our knowledge, there are no prior reports on $R$. oldhamii leaf extracts and its derivatives possessing antioxidant activity in vitro and hyperuricemic activity in vivo. Therefore, in this study, we investigated the hypouricemic effect of a methanolic extract and its major phytochemicals from $R$. oldhamii leaves in mice for the first time.

\section{Methods \\ Chemicals}

Benzbromarone, potassium oxonate, 1,1'-diphenyl-2picrylhydrazyl radical ( $\mathrm{DPPH} \cdot \mathrm{H}^{\cdot}$, hypoxanthine, xanthine oxidase, nitroblue tetrazolium chloride (NBT), FolinCiocalteu reagent, potassium dihydrogen phosphate $\left(\mathrm{KH}_{2} \mathrm{PO}_{4}\right)$, and $(+)$-catechin were purchased from Sigma Chemical Co. (St. Louis, MO, USA). The other chemicals and solvents used in this experiment were HPLC-grade.

\section{Plant materials}

The leaves of Rhododendron oldhamii Maxim. from Lion Head Mountain of Taipei county in Taiwan (Lat. $24^{\circ} 56^{\prime} 16^{\prime \prime N}$., Long. $121^{\circ} 30^{\prime} 07^{\prime \prime E}$.) were collected at the end of April 2011. The voucher specimen (voucher no. 6) was deposited at the herbarium of the Department of Forestry and Natural Resources, National Chiayi University (NCYU), Taiwan. The species were identified by Dr. Lei-Chen Lin (NCYU). The materials were air dried at ambient temperature $\left(25{ }^{\circ} \mathrm{C}\right)$ and stored in a refrigerator at $4{ }^{\circ} \mathrm{C}$ prior to treatments.

\section{Extraction, fractionation, and isolation}

Leaves were soaked in methanol at ambient temperature for 7 days. The extracts were decanted and filtered through Whatman No.1 filter paper, and the filtrates were concentrated in a rotary evaporator and then lyophilized. Furthermore, the resulting methanolic crude extracts of $R$. oldhamii were successively fractionated with $n$-hexane, ethyl acetate (EtOAc), $n$-butanol $(\mathrm{BuOH})$, and water to yield soluble fractions of hexane, EtOAc, $\mathrm{BuOH}$, and water. The phytochemicals from the EtOAc fraction were separated and purified by semi-preparative HPLC on a Jasco PU-2080 instrument (Tokyo, Japan) equipped with a MD-2010 photo-diode array detector (Jasco) and a $250 \mathrm{~mm} \times 10.0 \mathrm{~mm}$ i.d., 5- $\mu \mathrm{m}$ Supelco RPamide column (Bellefonte, PA, USA). The mobile phase was solvent A, $100 \% \mathrm{MeOH}$; and solvent $\mathbf{B}$, ultrapure water. The elution conditions were $0-15 \mathrm{~min}$ of $30-$ $60 \%$ A to B (linear gradient); $15-20$ min of $60-65 \%$ A to $\mathbf{B}$ (linear gradient); $20-27 \mathrm{~min}$ of $65-100 \% \mathbf{A}$ to $\mathbf{B}$ (linear gradient); and $27-40 \mathrm{~min}$ of $100-100 \% \mathbf{A}$ to $\mathbf{B}$ at a flow rate of $4 \mathrm{~mL} / \mathrm{min}$. ESI-MS data were collected by a Finnigan MAT-95S mass spectrometer, and NMR spectra were recorded by a Bruker Avance $500 \mathrm{MHz}$ FTNMR spectrometer. The structures of compound $\mathbf{1}$, compound $\mathbf{2}$, compound $\mathbf{3}$, compound $\mathbf{4}$, compound $\mathbf{5}$, and compound $\mathbf{6}$ were identified by ESI-MS and NMR.

\section{Quantification}

The phytochemicals were quantified by LC-MS (Thermo, Dioxed UltiMate 3000 UHPLC; Bruker, amazon speed) with a $250 \mathrm{~mm} \times 4.6 \mathrm{~mm}$ i.d., 2.6- $\mu \mathrm{m} \mathrm{C-18}$ column (Phenomenex, Torrance, CA, USA). The mobile phase was solvent A, $100 \% \mathrm{MeOH}$; and solvent $\mathbf{B}$, ultrapure water. The elution conditions were $0-15 \mathrm{~min}$ of $30-60 \%$ A to B (linear gradient); $15-20$ min of $60-65 \%$ A to B (linear gradient); $20-27 \mathrm{~min}$ of $65-100 \%$ A to B (linear gradient); and $27-40 \mathrm{~min}$ of $100-100 \% \mathbf{A}$ to $\mathbf{B}$ at a flow rate of $0.5 \mathrm{~mL} / \mathrm{min}$ using a detector. For the preparation of the calibration curve, standard stock solutions of compounds were prepared in methanol, filtered through Millipore filters $(0.45 \mu \mathrm{m})$, and appropriately diluted to obtain the desired concentrations in the 
quantification range. The calibration graphs were plotted after the linear regression of the peak areas versus concentrations.

\section{DPPH radical-scavenging activity (DPPH assay)}

The scavenging activity of the DPPH free radical by the test samples was determined according to the method reported by Ho et al. [20]. Ten $\mu \mathrm{L}$ of the test samples was mixed with $200 \mu \mathrm{L}$ of $0.1 \mathrm{mM}$ DPPH-ethanol solution and $90 \mu \mathrm{L}$ of $50 \mathrm{mM}$ Tris- $\mathrm{HCl}$ buffer (pH 7.4). Methanol $(10 \mu \mathrm{L})$ alone was used as the control in this experiment. After $30 \mathrm{~min}$ of incubation at room temperature, the reduction in DPPH free radicals was measured by reading the absorbance at $517 \mathrm{~nm}$ using a Thermo Scientific Multiskan GO microplate reader (Vantaa, Finland). $(+)$-Catechin was used as the positive control. The inhibition ratio was calculated using the following equation: \% inhibition $=[$ (absorbance of control - absorbance of test sample)/ absorbance of control] $\times 100$.

\section{Superoxide radical-scavenging activity (NBT assay)}

The measurement of superoxide radical-scavenging activity was carried out using the method described by Tung et al. [21], and (+)-catechin was used as the standard. First, $20 \mu \mathrm{L}$ of $15 \mathrm{mM} \mathrm{Na}_{2}$ EDTA in buffer $(50 \mathrm{mM}$ $\left.\mathrm{KH}_{2} \mathrm{PO}_{4} / \mathrm{KOH}, \mathrm{pH} 7.4\right), 50 \mu \mathrm{L}$ of $0.6 \mathrm{mM} \mathrm{NBT}$ in buffer, $30 \mu \mathrm{L}$ of $3 \mathrm{mM}$ hypoxanthine in $50 \mathrm{mM} \mathrm{KOH}, 5 \mu \mathrm{L}$ of the test samples in methanol, and $145 \mu \mathrm{L}$ of buffer were mixed in 96-well microplates (Falcon, USA). The reaction was initiated by adding $50 \mu \mathrm{L}$ of a xanthine oxidase solution in buffer ( 1 unit in $10 \mathrm{~mL}$ buffer) to the mixture. The reaction mixture was incubated at room temperature, and the absorbance at $570 \mathrm{~nm}$ was determined every $20 \mathrm{~s}$ up to $5 \mathrm{~min}$ using a plate reader. The control was $5 \mu \mathrm{L}$ of methanol instead of the sample solution. (+)-Catechin was used as the positive control. The inhibition ratio was calculated using the following equation: \% Inhibition $=[($ rate of control - rate of sample reaction)/ rate of control] $\times 100$.

\section{Reducing power assay}

This assay was determined according to the method reported by Lin et al. [16], with slight modifications. Briefly, $1 \mathrm{~mL}$ of the reaction mixture containing $500 \mu \mathrm{L}$ the test extracts or compounds in $500 \mu \mathrm{L}$ phosphate buffer (0.2 M, pH 6.6) was incubated with $500 \mu \mathrm{L}$ potassium ferricyanide $(1 \%, \mathrm{w} / \mathrm{v})$ at $50{ }^{\circ} \mathrm{C}$ for $20 \mathrm{~min}$. The reaction was terminated by adding trichloroacetic acid $(10 \%, \mathrm{w} / \mathrm{v})$, and the mixture was centrifuged at $3000 \mathrm{rpm}$ for $10 \mathrm{~min}$. The supernatant solution $(500 \mu \mathrm{L})$ was mixed with distilled water $(500 \mu \mathrm{L})$ and $100 \mu \mathrm{L}$ of ferric chloride $(0.1 \%, \mathrm{w} / \mathrm{v})$ solution, and the absorbance was measured at $700 \mathrm{~nm}$. The reducing ability was expressed as (+)-catechin equivalents $(\mathrm{CE})$ in milligrams per gram sample.

\section{Determination of total phenolics}

The total phenolic content was determined according to the Folin-Ciocalteu method [16], using gallic acid as the standard. The test sample (5 mg) was dissolved in $5 \mathrm{~mL}$ of methanol/water $(50: 50, \mathrm{v} / \mathrm{v})$. The extract solution $(500 \mu \mathrm{L})$ was mixed with $500 \mu \mathrm{L}$ of $50 \%$ Folin-Ciocalteu reagent. The mixture was kept for a 5-min period, which was followed by the addition of $1.0 \mathrm{~mL}$ of $20 \% \mathrm{Na}_{2} \mathrm{CO}_{3}$. After $10 \mathrm{~min}$ of incubation at room temperature, the mixture was centrifuged for $8 \mathrm{~min}(1200 \mathrm{~g})$ and the absorbance of the supernatant was measured at $730 \mathrm{~nm}$. The total phenolic content was expressed as gallic acid equivalents (GAE) in milligrams per gram sample.

\section{On-line DPPH radical-scavenging analysis}

The best antioxidant activity of the extract (EA fraction) from $R$. oldhamii leaves was further monitored by the on-line RP-HPLC-DPPH method. The EA fraction (stock concentration $=20 \mathrm{mg} / \mathrm{mL}$ ) was monitored by analytic HPLC on a model PU-2080 instrument (Jasco, Japan) with a $250 \mathrm{~mm} \times 10.0 \mathrm{~mm}$ i.d., 5 - $\mu \mathrm{m}$ Supelco RPamide column (Bellefonte, PA, USA). The mobile phase was solvent A, $100 \% \mathrm{MeOH}$; and solvent $\mathbf{B}$, ultrapure water. The elution conditions were $0-15 \mathrm{~min}$ of 30 $60 \%$ A to B (linear gradient); $15-20$ min of $60-65 \%$ A to $\mathbf{B}$ (linear gradient); $20-27 \mathrm{~min}$ of $65-100 \% \mathbf{A}$ to $\mathbf{B}$ (linear gradient); and $27-40 \mathrm{~min}$ of $100-100 \% \mathbf{A}$ to $\mathbf{B}$ at a flow rate of $4 \mathrm{~mL} / \mathrm{min}$, using a Jasco MD-2010 photo diode array at $280 \mathrm{~nm}$ wavelength. For the on-line DPPH radical-scavenging analysis, the flow of DPPH reagent $(300 \mathrm{mg} / \mathrm{L}$ in methanol) was set to $4 \mathrm{~mL} / \mathrm{min}$, and the induced bleaching was detected photometrically as a negative peak at $517 \mathrm{~nm}$.

\section{Animals}

Male ICR mice with a body weight of approximately $30 \mathrm{~g}$ (8 weeks old) were purchased from BioLASCO (A Charles River Licensee Corp., Yi-Lan, Taiwan). Mice were given a standard laboratory diet and distilled water ad libitum, and they were kept on a 12-h light/dark cycle at $22 \pm 2{ }^{\circ} \mathrm{C}$. All animal experimental protocols were approved by the Institutional Animal Care and Use Committee (IACUC) of National Taiwan Sport University, and the study conformed to the guidelines of the protocol IACUC-10319 approved by the IACUC ethics committee.

Potassium oxonate (PO) - induced hyperuricemia in mice For the hyperuricemia study, potassium oxonate (PO), an uricase inhibitor, was employed to induce acute hyperuricemia according to Tung et al. [22]. Sixty-four mice were randomly assigned to eight groups for treatment ( $n=8$ per group): (1) vehicle group; (2) PO group; (3) $\mathrm{PO}+\mathrm{BZM}$ group; (4) $\mathrm{PO}+\mathrm{EA}$ group; (5) $\mathrm{PO}+\mathrm{AS}$ 
group; (6) $\mathrm{PO}+\mathrm{HP}$ group; (7) $\mathrm{PO}+\mathrm{GJ}$ group; and (8) $\mathrm{PO}+\mathrm{QR}$ group. Briefly, mice were intraperitoneally (i.p.) injected with PBS containing PO (200 mg/kg) $1 \mathrm{~h}$ before the test samples were administered to increase the serum uric acid level. For a comparative study, the same dosage at $100 \mathrm{mmol} / \mathrm{kg}$ of the EtOAc fraction (EA, $45.0 \mathrm{mg} / \mathrm{kg}$ ), (2R, 3R)-astilbin (AS, $45.0 \mathrm{mg} / \mathrm{kg}$ ), hyposide (HP, $46.4 \mathrm{mg} / \mathrm{kg}$ ), guaijaverin (GJ, $43.4 \mathrm{mg} / \mathrm{kg}$ ), and quercitrin (QR, $44.8 \mathrm{mg} / \mathrm{kg}$ ) dissolved in DMSO were delivered i.p. for $1 \mathrm{~h}$ post $\mathrm{PO}$ administration. In this study, $10.0 \mathrm{mg} / \mathrm{kg}$ benzbromarone (BEM), a well-known uricosuric agent, was used as the reference control.

\section{Pathological histology}

Kidney tissue was fixed in $10 \%$ buffered formaldehyde and examined using hematoxylin and eosin (H\&E) staining.

Measurement of serum BUN, creatinine, and uric acid level Blood samples were collected by retro-orbital bleeding after $3 \mathrm{~h}$ PO administration. Blood samples were centrifuged at $1,400 \times g$ at $4{ }^{\circ} \mathrm{C}$ for $15 \mathrm{~min}$, and the levels of BUN, creatinine and uric acid in the serum supernatants were measured using an autoanalyzer (Hitachi 7060, Hitachi, Japan).

\section{Statistical analysis}

The data for in vitro and in vivo assays are expressed as the mean $\pm \mathrm{SD} \quad(n=3)$ and the mean $\pm \operatorname{SEM} \quad(n=8)$, respectively. The significance of difference was calculated by Scheffe's test, and the results with $P<0.05$ were considered to be statistically significant.

\section{Results and discussion}

DPPH radical-scavenging activity of $R$. oldhamii leaf extract and its derived soluble fractions

In the present study, the free radical-scavenging activity of $R$. oldhamii leaf extract was assessed by a DPPH assay. Accordingly, as shown in Fig. 1a, the DPPH radical-scavenging activity of the methanolic extract and its derived soluble fractions from leaves of $R$. oldhamii, including the soluble fractions of $n$-hexane, EtOAc, $\mathrm{BuOH}$, and water, were shown in a dose-dependent manner. Of these, the EtOAc fraction showed the strongest activity. Meanwhile, except for the $n$-hexane and water-soluble fractions, all extracts showed a good inhibitory activity against the $\mathrm{DPPH}$ radicals. The $\mathrm{IC}_{50}$ values (the concentration required to inhibit radical formation by $50 \%$ ) of the crude extract, hexane, EtOAc, $\mathrm{BuOH}$, and water fraction were $7.5 \pm 0.2,77.6 \pm 2.3$, $5.0 \pm 0.1,6.1 \pm 0.1$ and $30.0 \pm 0.6 \mu \mathrm{g} / \mathrm{mL}$, respectively. The $\mathrm{IC}_{50}$ value of (+)-catechin, a well-known antioxidant compound used as the reference control in this study,

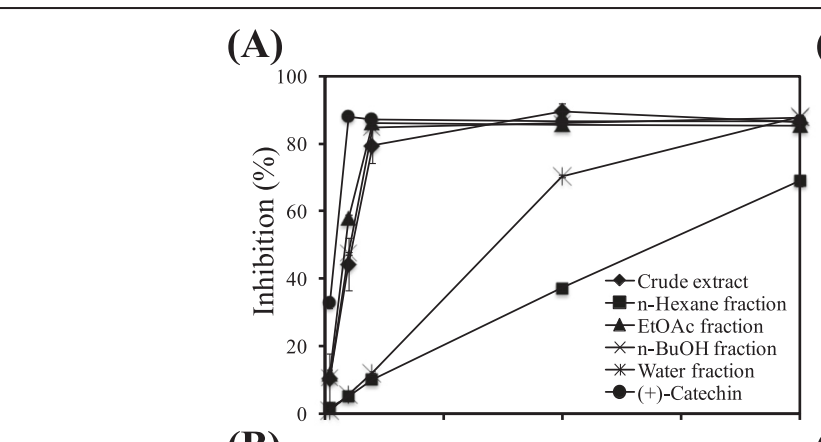

(B)

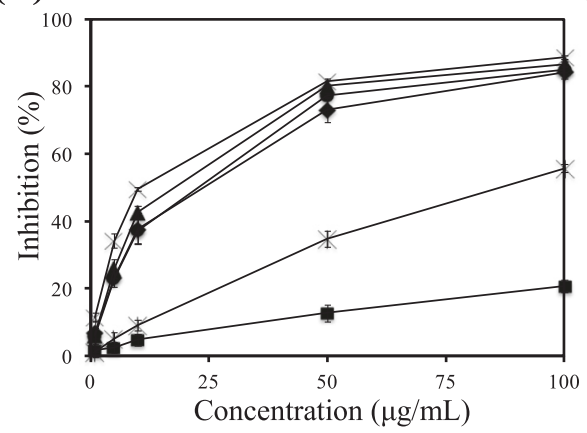

(C)

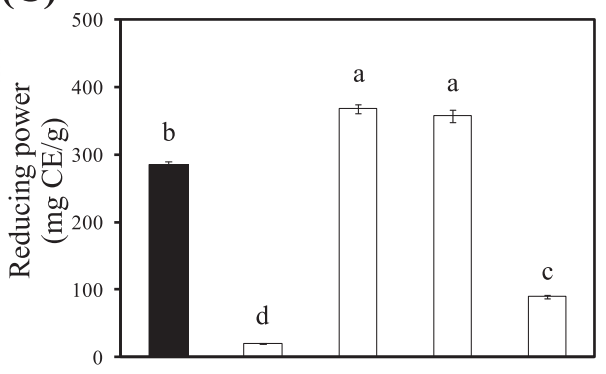

(D)

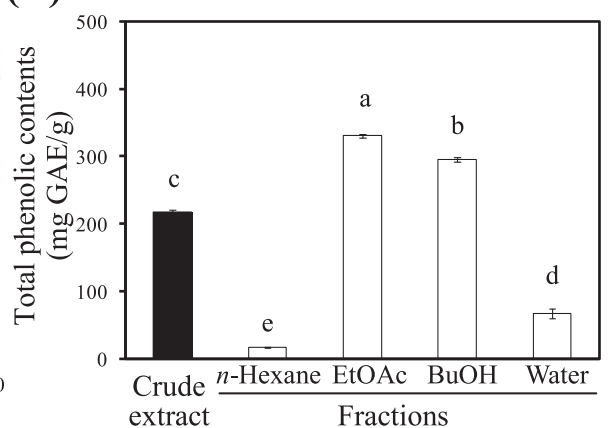

Fig. 1 Antioxidant activities of the methanolic extract and its derived soluble fractions from the leaves of $R$. oldhamii. a DPPH radical scavenging activity. $\mathbf{b}$ Superoxide radical scavenging activity. $\mathbf{c}$ Reducing power. $\mathbf{d}$ Total phenolic contents. The results are presented as the mean \pm SD ( $n=3$ ). The bars marked by different letters are significantly different at the level of $P<0.05$, according to Scheffe's test 
was $1.9 \pm 0.0 \mu \mathrm{g} / \mathrm{mL}$. Lin et al. [16] reported that the $\mathrm{IC}_{50}$ values of the crude extracts of Rhododendron species increased in the following order: $R$. pseudochrysanthum $(7.5 \mu \mathrm{g} / \mathrm{mL}), \quad R$. oldhamii $(7.5 \mu \mathrm{g} / \mathrm{mL}), \quad R$. kanehirai $(7.7 \mu \mathrm{g} / \mathrm{mL})$, R. breviperulatum $(8.8 \mu \mathrm{g} / \mathrm{mL})$, R. rubropilosum var. taiwanalpinum $(10.4 \mu \mathrm{g} / \mathrm{mL}), R$. formosanum (10.7 $\mu \mathrm{g} / \mathrm{mL})$, R. simsii $(11.8 \mu \mathrm{g} / \mathrm{mL})$, R. rubropilosum var. rubropilosum $(12.1 \mu \mathrm{g} / \mathrm{mL}), R$. ellipticum $(14.2 \mu \mathrm{g} / \mathrm{mL})$, and $R$. mariesii $(14.7 \mu \mathrm{g} / \mathrm{mL})$. These results showed that the crude extracts of the Rhododendron species exhibited a good DPPH radical scavenging activity.

\section{Superoxide radical-scavenging activity of $R$. oldhamii leaf} extract and its derived soluble fractions

Superoxide radical was generated by the hypoxanthinexanthine oxidase and NBT systems in this assay. Figure $1 \mathrm{~b}$ shows the superoxide radical-scavenging activity of the methanolic extract and its derived fractions from $R$.

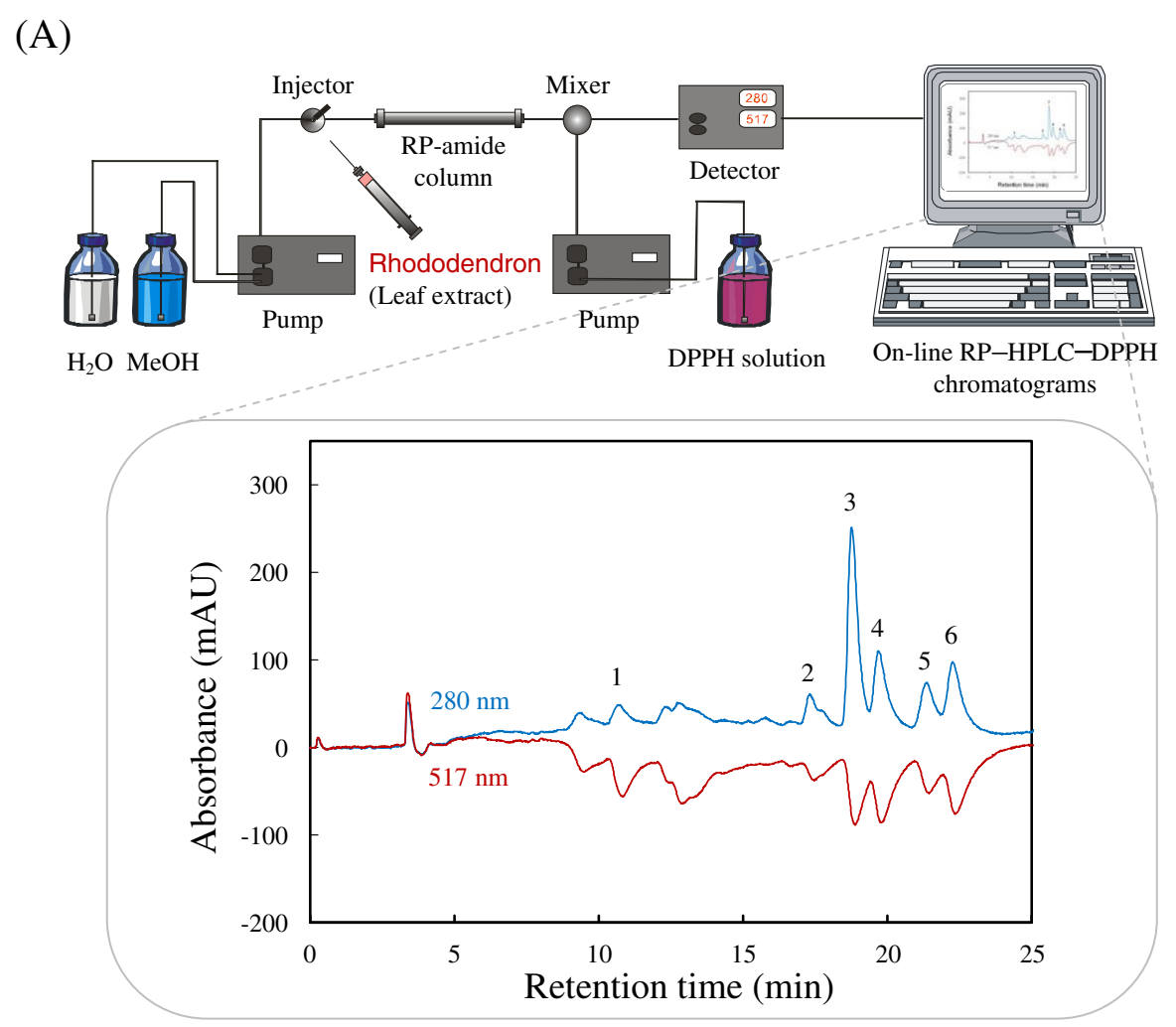

(B)<smiles>[R9]O[C@H]1C(=P)c2c(O)cc(O)cc2O[C@H]1c1ccc(O)c(O)c1</smiles><smiles>O=c1c(OP)c(-c2ccc(O)c(O)c2)oc2cc(O)cc(O)c12</smiles>
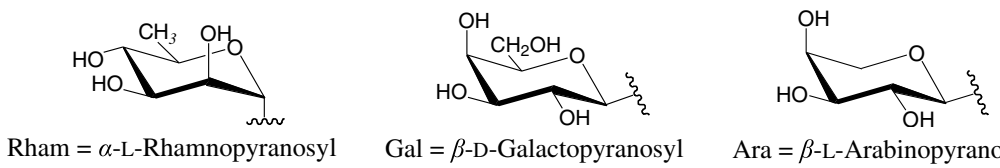

Fig. 2 a The online HPLC-DPPH chromatograms of the EtOAc fraction from $R$. oldhamii leaf extract. $\mathbf{b}$ Isolated and identified phytochemicals: $(2 R, 3 R)$-epicatechin (1), (2R, 3R)-taxifolin (2), (2R, 3R)-astilbin (3), hyposide (4), guaijaverin (5), and quercitrin (6) 
oldhamii leaves compared with $(+)$-catechin. At the $10 \mu \mathrm{g} / \mathrm{mL}$ test concentration, the superoxide radical inhibition of $R$. oldhamii leaf extract and its derived fractions decreased in the following order: $\mathrm{BuOH}$ fraction $(49.6 \%)>$ EtOAc fraction (42.6 \%) > crude extract $(37.7 \%)>$ water fraction $(9.1 \%)>n$-hexane fraction (4.7\%). The $\mathrm{IC}_{50}$ values of (+)-catechin, crude extract, $n$-hexane fraction, EtOAc fraction, $\mathrm{BuOH}$ fraction, and water fraction were $15.1 \pm 0.5,18 \pm 2.1,433.1 \pm 9.0$, $11.1 \pm 0.4,9.6 \pm 0.6$, and $60.1 \pm 4.8 \mu \mathrm{g} / \mathrm{mL}$, respectively. The comparisons of these data revealed that the crude extract, the EtOAc fraction, and the $\mathrm{BuOH}$ fraction examined in this study exhibited great superoxide radicalscavenging activity. The present study revealed that the EtOAc fraction and the $\mathrm{BuOH}$ fraction showed excellent performances in superoxide radical inhibition and their inhibitory activities were better than that of $(+)$-catechin. Lin et al. [16] showed that among all soluble fractions from $R$. pseudochrysanthum leaves, both the EtOAc fraction and the $\mathrm{BuOH}$ fraction exhibited the best superoxide radical-scavenging activity. This may be because the major components of the EtOAc and $\mathrm{BuOH}$ fractions were flavonoids and phenolic acids, which have great superoxide radical-scavenging effects.

\section{Reducing power of $R$. oldhamii leaf extract and its derived soluble fractions}

The reducing power of the crude extract and its derived fractions was calculated as $(+)$-catechin equivalents $(\mathrm{CE})$ in milligrams per gram sample. As shown in Fig. $1 \mathrm{c}$, the reducing power of the EtOAc fraction $(367.9 \pm 6.3 \mathrm{mg} / \mathrm{g})$ was higher than that of the $\mathrm{BuOH}$ fraction $(357.4 \pm 9.3 \mathrm{mg} / \mathrm{g})$, the crude extract $(285.2 \pm$ $4.1 \mathrm{mg} / \mathrm{g})$, the water fraction $(89.3 \pm 2.8 \mathrm{mg} / \mathrm{g})$, and the hexane fraction $(19.5 \pm 0.5 \%)$. These results revealed that the EtOAc fraction possessed the highest antioxidant activity, which was the same as the DPPH radical-scavenging activity results. These results imply that there is an abundance of antioxidative phytochemicals present in the EtOAc fraction.

Total phenolic contents of $R$. oldhamii leaf extract and its derived soluble fractions

Phenolic compounds are commonly found in the plant kingdom, and they have been reported to have multiple biological effects [23, 24]. A correlation between the content of phenolic compounds and antioxidant activities has been described in many studies [25-27]. The phenolic compounds are very important plant constituents because of their ability to scavenge free radicals. Figure $1 \mathrm{~d}$ shows the content of total phenolics in the crude extract and its derived fractions calculated as gallic acid equivalents (GAE) in milligrams per gram of sample. Apparently, the total phenolic content of the EtOAc fraction $(330.3 \pm 3.1 \mathrm{mg} / \mathrm{g})$ was higher than that of the $\mathrm{BuOH}$ fraction $(295.4 \pm 2.9 \mathrm{mg} / \mathrm{g})$, the crude extract $(217.6 \pm 2.4 \mathrm{mg} / \mathrm{g})$, the water fraction $(66.4 \pm 7.2 \mathrm{mg} / \mathrm{g})$, and the hexane fraction $(16.6 \pm 0.6 \mathrm{mg} / \mathrm{g})$. These results imply that there were abundant antioxidative phytochemicals present in the leaf extract of $R$. oldhamii, especially in the EtOAc fraction.

\section{On-line RP-HPLC-DPPH method}

The on-line RP-HPLC-DPPH method can be used for a rapid assessment of pure antioxidant compounds in complex mixtures, particularly plant extracts [28]. The more rapidly the absorbance decreases, the more potent the antioxidant activity of the compound will be in terms of hydrogen-donating ability [29]. The combined UV (positive signals) and $\mathrm{DPPH}^{*}$ quenching (negative signals) chromatograms under gradient conditions of the EtOAc fraction from the leaf extract of $R$. oldhamii are presented in Fig. 2a. Several eluted phytocompounds in the EtOAc fraction were detected and gave positive peaks on the UV detector $(280 \mathrm{~nm})$. Among them, $(2 R$, $3 R)$-epicatechin (1), $(2 R, 3 R)$-taxifolin $(2),(2 R, 3 R)$-astilbin (3), hyposide (4), guaijaverin (5), and quercitrin (6) (Fig. 2b) showed a hydrogen-donating capacity (negative peak) towards the DPPH radical at the applied concentration. The results revealed that the method can be applied for a quick screening of antioxidant compounds or to more precisely determine the radicalscavenging activity of compounds. Thus, it is no longer necessary to isolate and purify non-target phytocompounds, leading to very significant reductions in costs and faster results.

\section{Quantification and antioxidant activities of major active compounds in leaf extract of $R$. oldhamii}

According to the screening results from the on-line RP-HPLC-DPPH system, $(2 R, 3 R)$-epicatechin (1), $(2 R, 3 R)$-taxifolin $(2),(2 R, 3 R)$-astilbin (3), hyposide

Table 1 Antioxidant activities and contents of major phytochemicals of the EtOAc fraction from $R$. oldhamii leaves

\begin{tabular}{|c|c|c|c|}
\hline \multirow[t]{2}{*}{ Phytochemicals } & \multirow{2}{*}{$\begin{array}{l}\text { Content (mg/g } \\
\text { of EtOAc fraction) }\end{array}$} & \multicolumn{2}{|l|}{$\mathrm{IC}_{50}(\mu \mathrm{M})$} \\
\hline & & $\begin{array}{l}\text { DPPH radical } \\
\text { scavenging }\end{array}$ & $\begin{array}{l}\text { Superoxide radical } \\
\text { scavenging }\end{array}$ \\
\hline$(2 R, 3 R)$-Epicatechin (1) & $15.0 \pm 0.3$ & $8.4 \pm 0.2^{\mathrm{a}}$ & $34.1 \pm 1.3^{\mathrm{a}}$ \\
\hline$(2 R, 3 R)$-Taxifolin (2) & $27.0 \pm 0.4$ & $7.6 \pm 0.2^{\mathrm{abc}}$ & $17.9 \pm 1.0^{\mathrm{b}}$ \\
\hline$(2 R, 3 R)$-Astilbin (3) & $130.8 \pm 10.9$ & $8.2 \pm 0.5^{\mathrm{ab}}$ & $33.2 \pm 1.7^{\mathrm{a}}$ \\
\hline Hyperoside (4) & $105.5 \pm 8.5$ & $6.8 \pm 0.4^{c}$ & $16.1 \pm 0.3^{b c}$ \\
\hline Guaijaverin (5) & $104.1 \pm 4.7$ & $7.4 \pm 0.1^{b c}$ & $15.8 \pm 0.4^{\mathrm{bc}}$ \\
\hline Quercitrin (6) & $108.6 \pm 4.0$ & $6.9 \pm 0.2^{c}$ & $13.0 \pm 0.9^{c}$ \\
\hline
\end{tabular}

Different letters within a column indicate significant difference at the $P<0.05$ level according to Scheffe's test 
(4), guaijaverin (5) and quercitrin (6) were found to be the major bioactive phytochemicals in the EtOAc fraction, and their contents were determined to be $15.0 \pm 0.3$, $27.0 \pm 0.4, \quad 130.8 \pm 10.9, \quad 105.5 \pm 8.5, \quad 104.1 \pm 4.7$, and $108.6 \pm 4.0 \mathrm{mg}$ per gram of EtOAc fraction, respectively (Table 1). To determine the antioxidant activities of these major active compounds, DPPH and NBT assays were performed. As shown in Table 1, the $\mathrm{IC}_{50}$ values for the DPPH radical-scavenging activity of these major phytochemicals were $8.4 \pm 0.2,7.6 \pm 0.2,8.2 \pm 0.5$, $6.8 \pm 0.4, \quad 7.4 \pm 0.1$, and $6.9 \pm 0.2 \mu \mathrm{M}$, respectively. However, for superoxide radical-scavenging activity, the $\mathrm{IC}_{50}$ values of these compounds were $34.1 \pm 1.3$, $17.9 \pm 1.0,33.2 \pm 1.7,16.1 \pm 0.3,15.8 \pm 0.4$, and $13.0 \pm$ $0.9 \mu \mathrm{M}$, respectively. The DPPH and NBT assays showed that compounds $\mathbf{4}, \mathbf{5}$ and $\mathbf{6}$ had better activities. These results demonstrated that flavonoids containing the 2,3 double bond in the $\mathrm{C}$ ring have better antioxidant activities. In contrast, flavans have a saturated heterocyclic $\mathrm{C}$ ring, and the consequent lack of conjugation between the $\mathrm{A}$ and $\mathrm{B}$ rings means that electrons are less able to be delocalized from the $\mathrm{B}$ ring to the $\mathrm{A}$ ring, thus lowering their antioxidant activities.
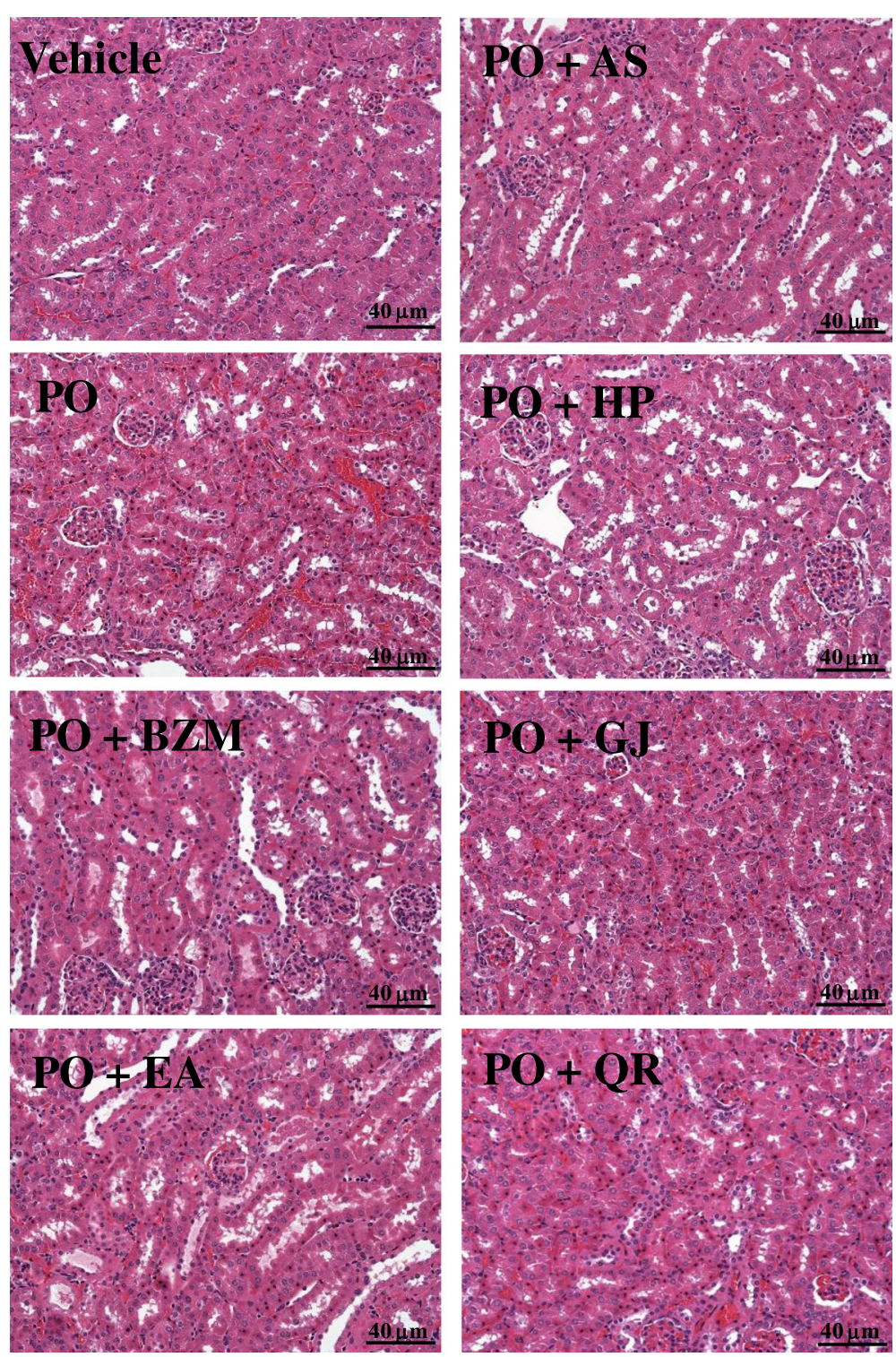

Fig. 3 The pathological histology of the EtOAc fraction and its derived phytochemicals of R. oldhamii leaf extract in PO-induced hyperuricemic mice. The H\&E staining showed that PO-induced kidney injury caused renal tubular epithelial nuclear condensation (karyopyknosis) in the cortex or the appearance of numerous hyaline casts in the medulla areas. The levels of renal tubular epithelial nuclear condensation or numerous hyaline casts were significantly reduced by benzbromarone, the EtOAc fraction, $(2 R, 3 R)$-astilbin, hyposide, guaijaverin, and quercitrin treatments 


\section{Anti-hyperuricemic effect in hyperuricemic mice}

Benzbromarone and allopurinol are widely used for the treatment of hyperuricemia. Allopurinol inhibits ROS production by working as an $\mathrm{XO}$ inhibitor but not as a radical scavenger, whereas benzbromarone decreases ROS production directly and indirectly by working as both a uric acid transporter 1 inhibitor and radical scavenger [30]. In this study, the major compounds of $R$. oldhamii leaf extract were good radical scavengers. Thus, the anti-hyperuricemic effect of $R$. oldhamii leaf extract and its phytochemicals on PO-induced hyperuricemia in mice was studied, and benzbromarone was the reference control used in this study. The hyperuricemic mice were generated by a single intraperitoneal injection of PO $(200 \mathrm{mg} / \mathrm{kg})$. PO, a urate oxidase inhibitor, can raise the serum uric acid concentration by inhibiting the decomposition of uric acid by uricase [31]. H\&E staining showed that PO-induced kidney injury caused renal tubular epithelium nuclear condensation (karyopyknosis) in the cortex or the appearance of numerous hyaline casts in the medulla areas (Fig. 3). The levels of renal tubular epithelial nuclear condensation or numerous hyaline casts were significantly reduced after the administration of $100 \mathrm{mmol} / \mathrm{kg}$ of EtOAc fraction, $(2 R, 3 R)$-astilbin, hyposide, guaijaverin, and quercitrin. Xiong et al. [32] also exhibited that NF- $\mathrm{kB}$ plays a role in the pathogenesis of chronic glomerulonephritis, and rhododendron root may attenuate renal damages by downregulating the activation of NF-kB. The hyperuricemic animals $3 \mathrm{~h}$ after i.p. of PO exhibited higher serum levels of BUN (40.2 \pm $1.2 \mathrm{mg} / \mathrm{dL})$, creatinine $(0.44 \pm 0.02 \mathrm{mg} / \mathrm{dL})$, and uric acid $(2.9 \pm 0.3 \mathrm{mg} / \mathrm{dL})$ when compared to the vehicle control group $(16.6 \pm 0.7,0.10 \pm 0.01$, and $0.8 \pm 0.1 \mathrm{mg} / \mathrm{dL}$, respectively). Therefore, at $3 \mathrm{~h}$ post PO injection, the serum uric acid level showed a more than 3 -fold increase compared with the vehicle control $(P<0.05)$. The administration of benzbromarone $(10 \mathrm{mg} / \mathrm{kg})$ significantly reduced the serum uric acid level by $45.5 \%$ compared to the PO group. At an equimolar dose $(100 \mathrm{mmol} / \mathrm{kg})$, animals treated with the EtOAc fraction, $(2 R, 3 R)$-astilbin, hyposide, guaijaverin, and quercitrin showed a significant reduction in uric acid by 54.1, 35.1, 56.3, 56.3, and $53.2 \%$, respectively, compared to the PO group $(P<0.05)$ (Fig. 4). In addition, treating hyperuricemic mice with benzbromarone, the EtOAc fraction, $(2 R, 3 R)$-astilbin, hyposide, guaijaverin, and quercitrin slightly reduced both creatinine and uric acid serum levels. Wang et al. [33] reported that cinnamaldehyde had good inhibitory activity on xanthine oxidase activity and could significantly reduce the serum uric acid level by $60 \%$ compared with the PO group at a dosage of $150 \mathrm{mg} / \mathrm{kg}$. Tung et al. [22] reported that the flavonoids of Acacia confusa heartwood, (-)-2,3-cis-3,4-cis3,3,4,4,7,8-hexahydroxyflavan, (-)-2,3-cis-3,4-cis-4'-methoxy-3,3,4,7,8-pentahydroxyflavan, melanoxetin, transilitin,

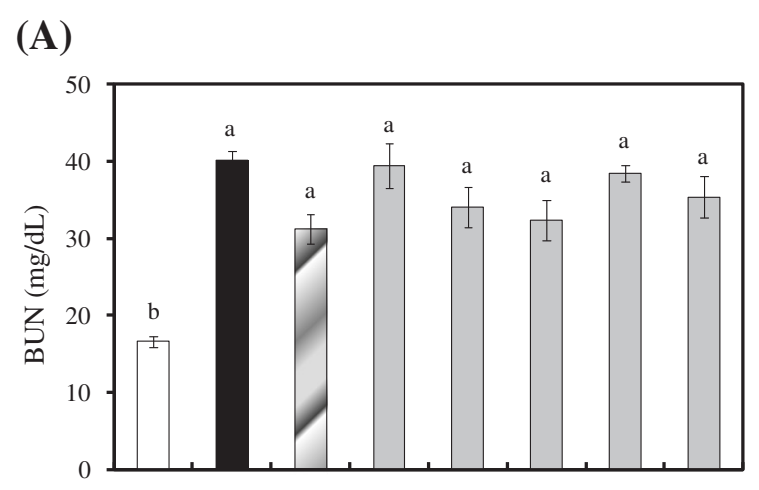

(B)

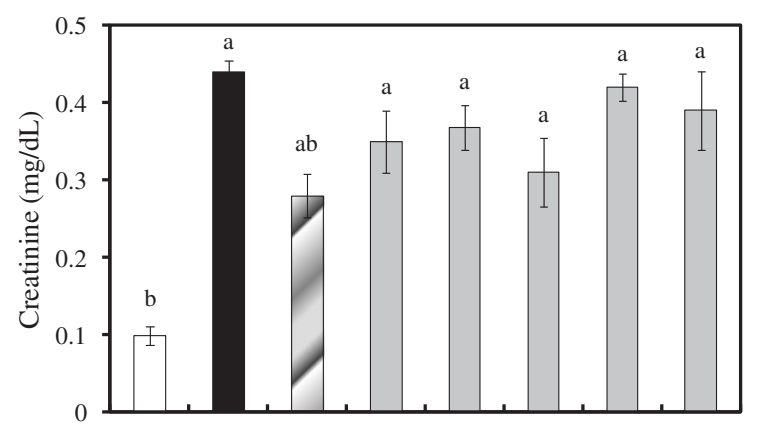

(C)

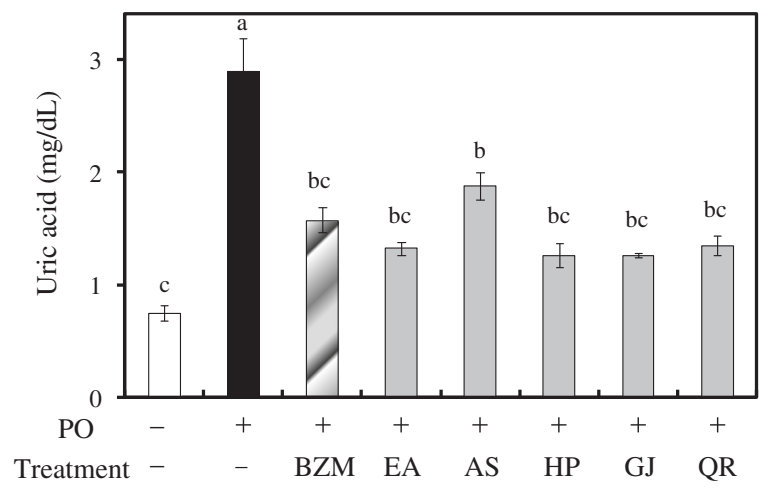

Fig. 4 The reductions in serum BUN, creatinine, and the uric acid level by the EtOAc fraction and its derived phytochemicals of $R$. oldhamii leaf extract in PO-induced hyperuricemic mice. The results are presented as the mean \pm SEM of eight mice. Different letters are significantly different at the level of $P<0.05$ according to the Scheffe's test

and okanin, showed good inhibitory activity on xanthine oxidase activity, and significantly reduced the serum uric acid level by $66,72,75,65$ and $69 \%$, respectively, compared with the PO group. Zhu et al. [34] also found that administration of the flavonoids quercetin and rutin significantly reduced the serum uric acid level by $36 \%$ and $32 \%$, respectively, at dosages of $150 \mathrm{mg} / \mathrm{kg}$. Comparisons of the aforementioned results indicated that the major flavonoids from the $R$. oldhamii leaf extract have an 
excellent effect on reducing urate levels. Among the flavonoid constituents examined, hyposide, guaijaverin, and quercitrin were comparable with benzbromarone and showed an excellent effect on reducing urate levels.

\section{Conclusion}

It is well-known that ROS have a high correlation with several diseases, such as ageing, atherosclerosis, inflammatory injury, cancer, and cardiovascular disease. This study demonstrated, for the first time, that among the leaf extracts of $R$. oldhamii, the EtOAc fraction exhibited the highest antioxidant activity. Thus, the EtOAc fraction was applied to the online HPLC-DPPH method, and six specific and excellent antioxidants were detected and identified. In addition, the study also demonstrated that the major constituents of $R$. oldhamii leaf extracts possessed potent in vivo hypouricemic effects in hyperuricemic mice pretreated with potassium oxonate. Thus, the dietary use of $R$. oldhamii leaf extracts and their constituents may provide some options for the prevention and/or treatment of hyperuricemia.

\section{Competing interests}

The authors declare no competing of interests.

\section{Authors' contributions}

Yu-Tang Tung, Chi-Chang Huang and Jyh-Horng Wu designed the experiments. Lei-Chen Lin, Ya-Ling Liu, Shang-Tse Ho, Chi-Yang Lin, Hsiao-Li Chuang, Chien-Chao Chiu, Chi-Chang Huang and Jyh-Horng Wu carried out the laboratory experiments. Yu-Tang Tung, Chi-Chang Huang and Jyh-Horng Wu analyzed the data, interpreted the results, prepared figures, and wrote the manuscript. All authors read and approved the final manuscript.

\section{Acknowledgement}

This work was financially supported by a research grant from the National Chung Hsing University.

\section{Author details \\ ${ }^{1}$ Graduate Institute of Sports Science, National Taiwan Sport University, Taoyuan 333, Taiwan. ²Department of Forestry and Natural Resources, National Chiayi University, Chiayi 600, Taiwan. ${ }^{3}$ Department of Forestry, National Chung Hsing University, Taichung 402, Taiwan. ${ }^{4}$ National Laboratory Animal Center, National Applied Research Laboratories, Taipei 11529, Taiwan. ${ }^{5}$ Division of Animal Resource, Animal Technology Laboratories, Agricultural Technology Research Institute, Hsinchu City 30093, Taiwan.}

Received: 19 September 2015 Accepted: 26 November 2015 Published online: 01 December 2015

\section{References}

1. Harris MD, Siegel LB, Alloway JA. Gout and hyperuricemia. Am Fam Physician. 1999;59:925-34.

2. Kramer HM, Curhan G. The association between gout and nephrolithiasis: the National Health and Nutrition Examination Survey III, 1988-1994. Am J Kidney Dis. 2002;40:37-42.

3. Tomita M, Mizuno S, Yamanaka H, Hosoda Y, Sakuma K, Matuoka Y, et al. Does hyperuricemia affect mortality? A prospective cohort study of Japanese male workers. J Epidemiol. 2000;10:403-9.

4. Lee JM, Kim HC, Cho HM, Oh SM, Choi DP, Suh I. Association between serum uric acid level and metabolic syndrome. J Prev Med Public Health. 2012:45:181-7.

5. Zoccali C, Mallamaci F. Uric acid, hypertension, and cardiovascular and renal complications. Curr Hypertens Rep. 2013;15:531-7.

6. Owen PL, Johns T. Xanthine oxidase inhibitory activity of northeastern North American plant remedies used for gout. J Ethnopharmacol. 1999;64:149-60.
7. Kong LD, Cai Y, Huang WW, Cheng CHK, Tan RX. Inhibition of xanthine oxidase by some Chinese medicinal plants used to treat gout. J Ethnopharmacol. 2000;73:199-207.

8. Sweeney AP, Wyllie SG, Shalliker RA, Markham JL. Xanthine oxidase inhibitory activity of selected Australian native plants. J Ethnopharmacol. 2001;75:273-7.

9. Chung JD, Lin TP, Chen YL, Cheng YP, Hwang SY. Phylogeographic study reveals the origin and evolutionary history of a Rhododendron species complex in Taiwan. Mol Phylogenet Evol. 2007;42:14-24.

10. Popescu R, Kopp B. The genus Rhododendron: an ethnopharmacological and toxicological review. J Ethnopharmacol. 2013;147:42-62.

11. Iwata N, Wang N, Yao X, Kitanaka S. Structures and histamine release inhibitory effects of prenylated orcinol derivatives from Rhododendron dauricum. J Nat Prod. 2004;67:1106-9.

12. Li QY, Chen L, Zhu YH, Zhang M, Wang YP, Wang MW. Involvement of estrogen receptor-B in farrerol inhibition of rat thoracic aorta vascular smooth muscle cell proliferation. Acta Pharmacol Sin. 2011;32:433-40.

13. Amit A, Parveen B, Vikas G, Ranjit S, Amrendra K. Pharmacological potential of medicinal plant used in treatment of gout. Drug Inven Tod. 2010;2:433-5.

14. Akram M, Usmanghani K, Ahmed I, Azhar I, Hamid A, Pak J. Comprehensive review on therapeutic strategies of gouty arthritis. Pharm Sci. 2014;27:1575-82.

15. Qiang Y, Zhou B, Gao K. Chemical constituents of plants from the genus Rhododendron. Chem Biodiver. 2011;8:792-815.

16. Lin CY, Lin LC, Ho ST, Tung YT, Tseng YH, Wu JH. Antioxidant activities and phytochemicals of leaf extracts from 10 native Rhododendron species in Taiwan. Evid-based Complement Altern Med. 2014;283938.

17. Chang WS, Lee YJ, Lu FJ, Chiang HC. Inhibitory effects of flavonoids on xanthine oxidase. Anticancer Res. 1993;13:2165-70.

18. Sampson L, Rimm E, Hollman PC, de Vries JH, Katan MB. Flavonol and flavone intakes in US health professionals. J Am Diet Assoc. 2002;102:1414-20.

19. Jung SJ, Kim DH, Hong YH, Lee JH, Song HN, Rho YD, et al. Flavonoids from the flower of Rhododendron yedoense var. poukhanense and their antioxidant activities. Arch Pharm Res. 2007;30:146-50.

20. Ho ST, Tung YT, Chen YL; Zhao YY, Chung MJ, Wu JH. Antioxidant activities and phytochemical study of leaf extracts from 18 indigenous tree species in Taiwan. Evid-based Complement Altern Med. 2012;215959.

21. Tung YT, Cheng KC, Ho ST, Chen YL, Wu TL, Wu JH. Comparison and characterization of the antioxidant potential of three wild grapes - Vitis thunbergii, V. flexuosa and V. kelungeusis. J Food Sci. 2011;76:C701-6.

22. Tung YT, Hsu CA, Chen CS, Yang SC, Huang CC, Chang ST. Phytochemicals from Acacia confusa heartwood extracts reduce serum uric acid levels in oxonate-induced mice: their potential use as xanthine oxidase inhibitors. J Agric Food Chem. 2010;58:9936-41.

23. Ricardo da Silva JM, Darmon N, Fernandez Y, Mitjavila S. Oxygen free radical scavenger capacity in aqueous models of different procyanidins from grape seeds. J Agric Food Chem. 1991;39:1549-52.

24. Sato M, Ramarathnam N, Suzuki Y, Ohkubo T, Takeuchi M, Ochi H. Varietal differences in the phenolic content and superoxide radical scavenging potential of wines from different sources. J Agric Food Chem. 1996;44:37-41.

25. Yen GC, Hsieh CL. Antioxidant activity of extracts from Du-zhong (Eucommia ulmoides) toward various lipid peroxidation models in vitro. J Agric Food Chem. 1998;46:3952-7.

26. Wangensteen $\mathrm{H}$, Samuelsen $A B$, Malterud KE. Antioxidant activity in extracts from coriander. Food Chem. 2004;88:293-7.

27. Chang ST, Wu JH, Wang SY, Kang PL, Yang NS, Shyur LF. Antioxidant activity of extracts from Acacia confusa bark and heartwood. J Agric Food Chem. 2001;49:3420-4.

28. Koleva II, Niederländer HAG, van Beek TA. An on-line HPLC method for detection of radical scavenging compounds in complex mixtures. Anal Chem. 2000;72:2323-8

29. Gadow A, Joubert E, Hansmann CF. Comparison of the antioxidant activity of aspalathin with that of other plant phenols of rooibos tea (Aspalathus linearis), a-tocopherol, BHT, and BHA. J Agric Food Chem. 1997:45:632-8.

30. Ohno I, Okabe H, Yamaguchi Y, Saikawa H, Uetake D, Hikita M, et al. Usefulness of combination treatment using allopurinol and benzbromarone for gout and hyperuricemia accompanying renal dysfunction: kinetic analysis of oxypurinol. Nippon Jinzo Gakkai Shi. 2008;50:506-12.

31. Tung YT, Chang ST. Inhibition of xanthine oxidase by Acacia confusa extracts and their phytochemicals. J Agric Food Chem. 2010;58:781-6.

32. Xiong J, Zhu Z, Liu J, Wang Y. The effect of root of rhododendron on the activation of NF-K B in a chronic glomerulonephritis rat model. J Nanjing Med Univ. 2009;23:73-8. 
33. Wang SY, Yang CW, Liao JW, Zhen WW, Chu FH, Chang ST. Essential oil from leaves of Cinnamomum osmophloeum acts as a xanthine oxidase inhibitor and reduces the serum uric acid levels in oxonate-induced mice. Phytomedicine. 2008;15:940-5.

34. Zhu JX, Wang Y, Kong LD, Yang C, Zhang X. Effects of Biota orientalis extract and its flavonoid constituents, quercetin and rutin on serum uric acid levels in oxonate-induced mice and xanthine dehydrogenase and xanthine oxidase activities in mouse liver. J Ethnopharmacol. 2004;93:133-40.

Submit your next manuscript to BioMed Central and we will help you at every step:

- We accept pre-submission inquiries

- Our selector tool helps you to find the most relevant journal

- We provide round the clock customer support

- Convenient online submission

- Thorough peer review

- Inclusion in PubMed and all major indexing services

- Maximum visibility for your research 